\title{
MHD Modeling of Conductors at Ultra-High Current Density
}

\author{
S. E. Rosenthal, Member, IEEE, M. P. Desjarlais, R. B. Spielman, W. A. Stygar, J. R. Asay, \\ M. R. Douglas, Member, IEEE, C. A. Hall, M. H. Frese, R. L. Morse, and D. B. Reisman
}

\begin{abstract}
In conjunction with ongoing high-current experiments on Sandia National Laboratories' $Z$ accelerator ${ }^{1}$ we have revisited a problem first described in detail by Heinz Knoepfel [1]. Unlike the 1-Tesla MITLs of pulsed power accelerators used to produce intense particle beams, Z's disc transmission line (downstream of the current addition) is in a 100-1200 Tesla regime, so its conductors cannot be modeled simply as static infinite conductivity boundaries. Using the MHD code $[2,3]$ MACH2 we have been investigating the conductor hydrodynamics, characterizing the joule heating, magnetic field diffusion, and material deformation, pressure, and velocity over a range of current densities, current risetimes, and conductor materials. Three purposes of this work are (1) to quantify power flow losses owing to ultra-high magnetic fields, (2) to model the response of VISAR [4] diagnostic samples in various configurations on $Z$, and (3) to incorporate the most appropriate equation of state and conductivity models into our MHD computations. Certain features are strongly dependent on the details of the conductivity model.
\end{abstract}

Index Terms- magnetic field diffusion, conductor hydrodynamics, electrical conductivity

\section{INTRODUCTION}

The development of very high current drivers has reopened a concern first voiced by Knoepfel [1] in which electrical losses at high current density were described. Later calculations by Singer and Hunter [5] extended Knoepfel's predictions to include losses due to mechanical work. Baker and Hussey [6] reexamined Singer's calculations and confirmed those results. Later Allshouse [7] used LASNEX [8], a 2-D RMHD code, to model conductor responses at the high current density levels predicted on next-generation drivers. Most recently, Reisman [9] and Stygar and Spielman [10] have examined

\footnotetext{
'Sandia is a multi-program laboratory operated by Sandia Corporation, a Lockheed Martin Company, for the United States Department of Energy under Contract DE-AC04-94AL8500.

S. E. Rosenthal, M. P. Desjarlais, R. B. Spielman, W. A. Stygar, J. R. Asay, M. R. Douglas, and C. A. Hall are with Sandia National Laboratories, Albuquerque, NM 87185-1194 USA.

(e-mail: serosen@sandia.gov).

M. H. Frese is with NumerEx, Inc, Albuquerque, NM.

R. L. Morse is with the University of New Mexico, Albuquerque, NM.

D. B. Reisman is with the Lawrence Livermore National Laboratory,

Livermore, CA.
}

the importance of model details and experiments on the prediction of electrical losses at high current densities.

The $Z$ accelerator generates up to $20 \mathrm{MA}$ of current. Normally this flows through a Z-pinch load at a typical

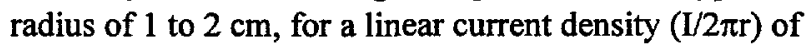
1.5 to $3 \mathrm{MA} / \mathrm{cm}$. New short-circuit hardware at a radius of only $3 \mathrm{~mm}$ permits, for the first time, the possibility of detailed measurements of the losses in conductors at current densities as high as $10 \mathrm{MA} / \mathrm{cm}$ on $\mathrm{Z}$. Simultaneously, improvements in the tabulated values of the resistivities of several elements allows greatly improved calculations of the losses in conductors. This information has gained added importance with plans to build larger pulsed-power drivers having current densities approaching $10 \mathrm{MA} / \mathrm{cm}$ at typical $Z$-pinch load radii. Clearly, before proceeding to build such drivers, we must learn whether loss mechanisms exist that fundamentally limit the current density in a conductor.

Treating the magnetic diffusion as a linear problem with constant resistivity shows that diffusion and corresponding Joule heating would be significant at current densities in the $1-10 \mathrm{MA} / \mathrm{cm}$ range. Considering an assumed functional dependence of resistivity on heat energy $[1,5,11]$ provides a simplified description of nonlinear magnetic diffusion, providing a pessimistic upper limit of losses that scale with the cube of the current density. In this paper we describe our effort to study diffusion and heating consistently with a MHD code. For this study we have employed electrical conductivities that are accurate over the wide range of densities and temperatures important for this problem. Such conductivity information has not previously been available for use in a MHD calculation.

\section{MODEL DESCRIPTION}

\section{A. Brief Description of $M A C H 2$}

The MACH2 Code solves the time-dependent magnetohydrodynamics (MHD) equations on a blockstructured grid composed of arbitrary hexahedrals. The code is of the ALE (Arbitrary Lagrangian-Eulerian) variety which allows the grid to move independently of the magnetofluid. The physical processes included in the model are diffusion, Lagrangian hydrodynamics, and advection. Details of the algorithms are provided in references 2 and 3.

The geometrical domain is block structured which allows for the modeling of complex geometries. MACH2 allows for numerous boundary conditions in the 2-D plane which 


\section{DISCLAIMER}

This report was prepared as an account of work sponsored by an agency of the United States Government. Neither the United States Government nor any agency thereof, nor any of their employees, make any warranty, express or implied, or assumes any legal liability or responsibility for the accuracy, completeness, or usefulness of any information, apparatus, product, or process disclosed, or represents that its use would not infringe privately owned rights. Reference herein to any specific commercial product, process, or service by trade name, trademark, manufacturer, or otherwise does not necessarily constitute or imply its endorsement, recommendation, or favoring by the United States Government or any agency thereof. The views and opinions of authors expressed herein do not necessarily state or reflect those of the United States Government or any agency thereof. 


\section{DISCLAIMER}

Portions of this document may be illegible in electronic image products. Images are produced from the best available original document. 
are specified by the user. An important feature is that new EOS/conductivity/opacity models are easily implemented.

\section{B. Geometries}

The geometry for the simulations corresponds to the disc/coaxial load configuration shot on the $Z$ high-currentdensity power flow experiments. The usual load shot on $Z$ for high-energy-density physics experiments is illustrated in the three-dimensional rendering of Fig. 1 . In this load a cylindrical wire array comprises the cathode of the inner coax. Power flows radially inward in the disc to the inner coax. An alternate load, specially contrived to carefully study the effects of ultra-high current $(\sim 10 \mathrm{MA} / \mathrm{cm}$ linear current densities) on $\mathrm{Z}$ is shown in the $\mathrm{Z}$-r cross-section schematic of Fig. 2. The inner coax has a 6-mm inner conductor diameter, smaller than used in Fig. 1, and a 12$\mathrm{mm}$ outer-conductor diameter. The length of the coaxial section is $2.2 \mathrm{~cm}$. Again, power flows radially inward. The conductor material for the high-current-density experiment and simulations is $304 \mathrm{~L}$ stainless steel. Region 1 of Fig. 2 defines the geometry for the MACH2 simulations of the high-current-density load. We have also considered only a portion of the disc for a simpler geometry in some simulations, indicated by region 2 . These simulations considered both iron and copper as conductor materials. The simulations typically employed an Eulerian mesh and were repeated in some cases using a Lagrangian mesh to test how well the highest-density material was resolved in regions of compression.

\section{ELECTRICAL CONDUCTIVITY MODEL}

The fidelity of our $\mathrm{MACH} 2$ calculations depends largely upon an accurate knowledge of the material resistivities over a wide range of temperatures and densities. Of particular importance for these simulations is the regime defined by temperatures below a few $\mathrm{eV}$ and densities below solid, especially in the vicinity of the metal-insulator transition. In recent years, DeSilva and colleagues [12] have performed numerous experiments with $\mathrm{Cu}, \mathrm{Al}$, and $\mathrm{W}$ wires with particular emphasis on this regime. It is clear that the commonly used Lee-More [13] and SESAME (Rinker [14]) resistivities, developed for higher density and temperature applications, are not very accurate in this parameter range, often differing from the data by several orders of magnitude.

We have recently developed a modified Lee-More algorithm that smoothly blends into the standard Lee-More results outside of this regime, but is modified in such a way as to give good agreement with the experimental data of DeSilva [15]. The nature of the modifications is such that reasonable electrical conductivities can be estimated for materials for which extensive data do not yet exist. This modified Lee-More algorithm is used to generate SESAME format conductivity tables for use in MACH2. Consistent mean ion charge state and thermal conductivity tables can also be generated. These replace the "Category 3" SESAME tables.

New tables have been generated for stainless steel, tungsten, titanium, iron, aluminum, and copper. A set of constant-temperature conductivity curves for stainless steel is shown in Fig. 3a. A significant feature that is not exhibited by previously used conductivity models is the weak temperature dependence constituting the metalinsulator transition (in the vicinity of $\log _{10} \rho \sim 0$ ). A typical comparison between the previous models and the new model with data is shown in Fig. $3 \mathrm{~b}$ for copper at a temperature of $6000 \mathrm{~K}$. The discrepancy between previously available conductivities and data is quite large for densities below solid.

Metals conducting currents of ultra-high density occupy this low-density-few-eV regime during the processes we are studying, such as magnetic field diffusion, joule heating, and material ablation. The wires of a Z-pinch load also enter this density-temperature regime during the process of changing from cold metal to warm plasma while conducting large currents. Hence it is imperative to use accurate conductivities for calculations in this regime.

Figure 4 illustrates the effect of using conductivities that are much too low in a MACH2 simulation of a copper disc (region 2 of Fig. 2). Current flows radially inward and is given by a 100 -ns ramp to a constant $20 \mathrm{MA}$. After $100 \mathrm{~ns}$ at full current, ablated material, too resistive to be trapped by the magnetic field, extends $0.5 \mathrm{~mm}$ into the original vacuum gap. This mass density corresponds to an electron density of up to $10^{22} \mathrm{~cm}^{-3}$ and would present a serious limitation to power flow.

As Fig. 3b illustrates, the Modified Lee-More conductivity tables are a vast improvement over previous models below solid density. The more accurate, higher conductivity of the low-density ablated material given by the Modified Lee-More table prevents the ablated material from diffusing across the magnetic field into the vacuum gap.

Viewing the density profile on a log scale reveals that a density of up to one thousandth of solid exists $0.1 \mathrm{~mm}$ above the initial metal surface and is $0.1 \%$ ionized. This corresponds to an electron density in the $10^{16} \mathrm{~cm}^{-3}$ range. This would probably not prevent efficient current conduction, but the result suggests that the issue of plasma developing in the power-flow gaps of high-current-density accelerators might be important and needs much more study. These plasmas cannot be properly described by fluid models.

Accurate electrical conductivities provide us with a prerequisite for meaningful simulations in our parameter regime. We can explore the qualitative nature of energy absorption near the conductor; e.g., is significant plasma evolution into the gap expected? Quantitative comparisons can be made with experiment, leading to refinements in other areas of the simulation model that might be deficient. 


\section{SIMULATIONS OF HIGH-CURRENT LOAD}

The MACH2 calculations of stainless steel in the region1 geometry show the preferential heating found in the regions of highest current density. Careful examination of the calculations reveals significant diffusion of magnetic field into the conductor as well as conductor motion (and density increase) driven by the gradient of the magnetic pressure. Because of the dependence of losses on current density nearly all of the dissipation occurs in the inner coaxial region of the load.

The top of Fig. 5 shows a snapshot of the azimuthal magnetic field at the time of peak current. Below in Fig. 5 is the profile taken along the line indicated at $z=10 \mathrm{~mm}$. One can see the usual $1 / \mathrm{r}$ dependence of the field in the vacuum gap $(3<\mathrm{r}<6 \mathrm{~mm})$, and the diffusion that occurs into the metal, to the left at $r=3 \mathrm{~mm}$, and to the right at $r=$ $6 \mathrm{~mm}$. The linear current density is roughly $10 \mathrm{MA} / \mathrm{cm}$ at $\mathrm{r}$ $=3 \mathrm{~mm}$, and $5 \mathrm{MA} / \mathrm{cm}$ at $6 \mathrm{~mm}$.

The profile of mass density along the $\mathrm{z}=10 \mathrm{~mm}$ line (Fig. 5a) shows in Fig. 6 the lack of mass in the original gap. It also shows the different degrees of compression corresponding to $10 \mathrm{MA} / \mathrm{cm}$ near $\mathrm{r}=3 \mathrm{~mm}$, and $5 \mathrm{MA} / \mathrm{cm}$ at $6 \mathrm{~mm}$. The density is compressed just below the conductor surfaces, the compressed region extending deeper into the metal on the $10 \mathrm{MA} / \mathrm{cm}$ side than the 5 $\mathrm{MA} / \mathrm{cm}$ side. Correspondingly, the density at the conductor surface falls below its original value. Hence, most of the current on the inner-radius conductor flows where the density is below $7.896 \mathrm{gm} / \mathrm{cm}^{3}$ and therefore at greater resistivity than normal, although above $2.5 \mathrm{eV}$ the difference is small for a factor of 4 drop in density. This behavior in the resistivity is shown by the constant-density curves of Fig. 7. The low-density material reaches a temperature of $2 \mathrm{eV}$ by $120 \mathrm{~ns}$ into the $\mathrm{Z}$ power power pulse, near the time of peak current.

Finally, figure 8 shows the Joule heating rate, maximum at the inner coaxial surface, extending into the metal by 1 $\mathrm{mm}$. More radial resolution is needed to capture the actual peak near $2.8 \mathrm{~mm}$.

Using reasonably accurate resistivity information, the MHD simulations can now provide a meaningful description of our high-current density problem. An important conclusion has emerged from this ongoing effort: negligible conductor material enters the gap, even at the highest current density considered. Ablative material in the $2-4 \mathrm{eV}$ temperature range is sufficiently conductive (200$600 \mu \Omega-\mathrm{cm})$ to be held against the solid conductor by the magnetic pressure for the time of the pulse.

Shots on $\mathrm{Z}$ using the configuration of Fig. 2 and the analysis of the data are ongoing and have not yet reached the desired level of confidence for publication. The experimental results will eventually be compared in detail to these simulations. Applying the magnetic field corresponding to the measured load current waveform as a boundary condition at the simulation disc inlet $(\mathrm{r}=13 \mathrm{~mm})$ yields a simulated loss that will be compared to energy loss measured on $\mathrm{Z}$ shots. This will be done for both stainless steel and copper conductors.

\section{SIMULATIONS OF VISAR SAMPLES}

In the disc geometry (region 2 of Fig. 2) we considered the magnetic diffusion into a thick $(2 \mathrm{~mm})$ sample of iron or copper. The schematic is shown in Fig. 9. A linearly ramped current density of $2 \mathrm{MA} / \mathrm{cm}$ (or equivalently, a magnetic pressure of $250 \mathrm{kbar}$ ), reached in $100 \mathrm{~ns}$, is assumed. This corresponds to a current of about $15 \mathrm{MA}$ at the radius of $1.2 \mathrm{~cm}$ in region 2 .

The 2-mm sample thickness of the simulations exceeds the usual experimental VISAR sample thickness which is less than $1 \mathrm{~mm}$. VISAR measurements of the rear surface of material that is isentropically compressed by magnetic pressure demand two limitations on sample thickness. The sample must be thin enough to avoid the development of a shock, while sufficiently thick to prevent the magnetic field from diffusing all the way through the sample to the VISAR side, where it would interfere with the rear surface velocity measurement. The simulations help determine the feasability of VISAR isentropic compression experiments for a given material, sample thickness, and current density.

The MACH2 simulations show hydrodynamic pressure resulting from the applied magnetic pressure on the conductor surface, using our new conductivity model and SESAME EOS. The hydro pressure runs ahead (deeper in the sample) of the magnetic pressure, exhibiting in Figs. 10 and 11 structure indicative of the $\alpha-\varepsilon$ phase transition in iron. Note that the small pressure shown ahead of the pulse $(z>1 \mathrm{~mm})$ is the pressure the SESAME equation of state table assigns to the iron at room temperature, even though it is in the solid state.

For comparison the simulation was repeated using a constant resistivity $(9.8 \mu \Omega-\mathrm{cm})$ to show the effects of nonlinear diffusion. The heating and pressure changes in a conductor associated with the diffusion of very large magnetic fields lead to changes in the conductivity, which in turn affects the diffusion. Because the iron resistivity at solid density increases by more than a factor of 10 for a temperature rise of only 700 degrees $\mathrm{K}(0.06 \mathrm{eV})$, as shown in Fig. 12, the magnetic diffusion is significantly greater than one would predict from constant resistivity at room temperature solid density.

The same simulations done for a copper sample behave as seen in Figs. 13 and 14. Again, the hydro pressure runs ahead of the magnetic pressure. Copper is much more conductive than iron, so the magnetic field diffuses less during the time of the pulse $(0.3 \mathrm{~mm}$ compared to $0.75 \mathrm{~mm}$ for iron). In Figs. 13 and 14 the results are compared to those obtained using the original SESAME conductivity table for copper. As one would expect from Fig. 3b, which shows a dramatic over-estimate of copper's resistivity by the SESAME 23334 table, the calculation using the original SESAME conductivity table shows significantly greater diffusion depth of the magnetic field.

Results for a current density of $5 \mathrm{MA} / \mathrm{cm}$ (linearly ramped in $100 \mathrm{~ns}$ ) show that an iron sample thickness that would prevent magnetic field from reaching the back surface $(>1.1 \mathrm{~mm}, 100 \mathrm{~ns}$ after peak current) exceeds the 
maximum allowed to maintain isentropic compression. In copper the magnetic field diffuses to a depth of only 0.65 $\mathrm{mm} 100 \mathrm{~ns}$ after peak, allowing a sample that is thin enough to avoid shock development. These simulations suggest that the conflicting thickness requirements can be met, although with different upper limits on current density appropriate for different materials and time scales.

\section{SUMMARY}

New, accurate conductivity tables for a variety of materials have enabled us to begin interesting inquiries into the behavior of conductors under ultra-high pressures associated with $1-10 \mathrm{MA} / \mathrm{cm}$. Results indicate that ablation of conductor material into the power flow gap is insignificant and should not prevent efficient current conduction at current densities below $10 \mathrm{MA} / \mathrm{cm}$.

Meaningful hydrodynamic simulations can be done of isentropic compression experiments that rely on magnetic diffusion at ultra-high current densities.

\section{ACKNOWLEDGEMENTS}

The authors wish to thank Alan DeSilva for sharing his most recent data on electrical conductivity of copper, tungsten, and aluminum. The reviewers' comments and suggestions are also gratefully acknowledged.

\section{REFERENCES}

[1] H. Knoepfel, Pulsed High Magnetic Fields, North Holland Publishing Company, London, UK, 1970.

[2] MACH Reference Manual by R. E. Peterkin, Jr. and M. H. Frese, July 1998. The code must not be distributed without written permission from the Air Force Research Laboratory: Phillips Research Site, Kirtland AFB, NM.

[3] M. H. Frese, "MACH2: A Two-Dimensional Magnetohydrodynamic Simulation Code for Complex Experimental Configurations", AMRC-R-874, Mission Research Corporation, 1987. R. E. Peterkin, Jr., M. H. Frese, and C. R. Sovinec, "Transport of magnetic flux in an arbitrary coordinate ALE code", J. Comput. Phys., vol. 140, p. 148, Feb. 1998.

[4] Velocity Interferometer System for Any Reflector; L. M. Barker and R. E. Hollenbach, J. Appl. Phys. 43, 4669 (1972). L. M. Barker and R. E. Hollenbach, J. Appl. Phys. 45, 4872 (1974). J. R. Asay, et al., "ZPinch Drivers for Shock Physics Research", Proc. Of the Eighth Int. Conf. On Megagauss Magnetic Fields and Applications, Tallahassee, FL. 1998.
[5] S. Singer and R. O. Hunter, Proc. of the Third IEEE Pulsed Power Conf., Albuquerque, NM 1981, p. 351.

[6] L. Baker and T. W. Hussey, "Energy Loss in High Current Density Feeds", Sandia National Laboratories Internal Memorandum, 2 December 1981.

[7] G. O. Allshouse, "Energy Loss in a High Power Transmission Line", Sandia National Laboratories Internal Memorandum, 30 October 1996.

[8] G. B. Zimmerman, Lawrence Livermore National Laboratory, UCRL-74811, 1973.

[9] D. B. Reisman, "Numerical simulation of fiber and wire array Z-pinches with Trac-II", UCRL-LR-131742, Lawrence Livermore National Laboratory, 1998.

[10] W. A. Stygar and R. B. Spielman, "Calculation of Energy Loss to Conductors at High Current Densities", Sandia National Laboratories Internal Memorandum, 8 July 1998. W. A. Stygar, et al., Bull. Am. Phys. Soc. 43, p. 262 (1998). R. B. Spielman, et al., Proc. of the Eleventh IEEE Pulsed Power Conf., Baltimore, MD 1997, p. 709.

[11]D. Parks, et al, "Advanced Simulator Power . Flow Technology/Advanced Radiation Simulation, Vol. II", Maxwell-S-Cubed Div. Report SSS-DTR-96-15347 (July 1996).

[12] A. W. DeSilva and J. D. Katsouros, Phys. Rev. E 57, 5945 (1998).

[13] Y.T. Lee and R.M. More; Phys. Fluids 27, 1273 (1984).

[14] G.A. Rinker, Phys. Rev. A 37, 1284 (1988).

[15] M. P. Desjarlais, S. E. Rosenthal, and R. B. Spielman, Bull. Am. Phys. Soc. 44, p. 33 (1999)

[16] Electrical Resistivity Handbook, ed. by G. T. Dyos and T. Farrell, Peter Peregrinus Ltd., London, 1992. 


\section{FIGURE CAPTIONS}

[1] Typical load configuration on the $\mathrm{Z}$ accelerator. The $\mathrm{MACH} 2$ simulation region corresponds to a cross section of the disc to inner coaxial MITL.

[2] A drawing of the new coaxial short-circuit load (inside the convolute radius) that is used to develop high current densities. The locations of the B-dot current monitors and the VISAR probes are shown. Simulation region 1 includes radius from the axis to $13 \mathrm{~mm}$, and $\mathrm{z}$ $=1$ to $27 \mathrm{~mm}$. The coax AK gap occurs from $\mathrm{r}=3$ to $6 \mathrm{~mm}$, the metal exists between $\mathrm{r}=0$ and $3 \mathrm{~mm}$ and between $\mathrm{r}=6$ and $8 \mathrm{~mm}$. The metal end cap (short) bridges the coax at $\mathrm{z}=25 \mathrm{~mm}$ and is $2 \mathrm{~mm}$ thick axially. The entrance to the disc is at $r=13 \mathrm{~mm}$. The lower disc conductor exists between $\mathrm{z}=1$ and $3 \mathrm{~mm}$; the upper disc conductor exists between 9 and $11 \mathrm{~mm}$. Region 2 includes radius from 3 to $13 \mathrm{~mm}$, and $\mathrm{z}=3$ to $7 \mathrm{~mm} ; \mathrm{z}=3$ to $5 \mathrm{~mm}$ is metal, and 5 to $7 \mathrm{~mm}$ vacuum.

[3] 3a) A subset of constant-temperature conductivity curves from our modified Lee-More model for stainless steel; 3b) The $6000 \mathrm{~K}(0.5 \mathrm{eV})$ copper conductivity curves from both the original Lee-More model and Rinker model (taken from the original SESAME conductivity table no. 23334 for copper), with data obtained by A. DeSilva, are compared to the modified Lee-More 6000K curve for copper.

[4] z-r snapshots (first row) and corresponding axial lineouts (second row) for the lower conductor of a copper disc between $r=3$ and $13 \mathrm{~mm}$. The lineout is taken at $\mathrm{r}=5.5 \mathrm{~mm}$ where the current density $(\mathrm{I} / 2 \pi \mathrm{r})$ is $5.8 \mathrm{MA} / \mathrm{cm}$. Initially, vacuum exists above $\mathrm{z}=5 \mathrm{~mm}$, and room-temperature solid copper $\left(\rho=8.93 \mathrm{gm} / \mathrm{cm}^{3}\right)$ occupies the space below $5 \mathrm{~mm}$. (See region 2 of Fig. 2.) In the z-r snapshot vacuum is black, and the highest density is white. The lineouts are shown only over the low-density region in the vicinity of the original metal surface. Rinker resistivities (original SESAME table no. 23334) were used in the simulation on the left, and our new model (SESAME table no. 29333) on the right.

[5] $\mathrm{MACH} 2$ simulation results for region 1 of Fig. 2; 5a) The azimuthal component, $B_{\Theta}$, of the magnetic field at the time of peak current in grayscale contours, where the lightest shades correspond to the highest field; $5 \mathrm{~b}$ ) The profile of $B_{\Theta}(r)$ at $z=10 \mathrm{~mm}$ (along the line indicated in $5 \mathrm{a}$ ).

[6] A radial profile of the conductor mass density (taken along the line indicated in Fig. 5a). Dashed curve is at $t$ $=0$, solid curve is at time of peak current.

[7] A set of three constant-density conductivity curves for stainless steel as a function of temperature, from our modified Lee-More model.
[8] A radial profile (taken along the line indicated in Fig. 5a) of the Joule heating rate at time of peak current.

[9] A simple schematic for the simulations of material samples subjected to pressure from magnetic diffusion.

[10] Profiles of magnetic and hydro pressure $50 \mathrm{~ns}$ after peak applied field ( $2 \mathrm{MA} / \mathrm{cm}$ ), comparing $\mathrm{MACH} 2$ simulation results using a constant electrical conductivity (resistivity $=9.8 \mu \Omega-\mathrm{cm}$ ) for iron with results using the modified-Lee-More conductivity table for iron.

[11] Profiles of magnetic and hydro pressure in iron $100 \mathrm{~ns}$ after peak applied field (2 MA/cm).

[12] The low-temperature (300-3000 degrees $\mathrm{K}$ ) behavior of iron resistivity at normal solid density $\left(7.85 \mathrm{gm} / \mathrm{cm}^{3}\right)$. The curve is from our new model, and the data points are from ref. 16.

[13] Profiles of magnetic and hydro pressure $50 \mathrm{~ns}$ after peak applied field ( $2 \mathrm{MA} / \mathrm{cm}$ ), comparing $\mathrm{MACH} 2$ simulation results using the original SESAME conductivity (table 23334) with results using the modified-Lee-More conductivity (table 29333) for copper.

[14] Profiles of magnetic and hydro pressure in copper 100 ns after peak applied field $(2 \mathrm{MA} / \mathrm{cm})$. 


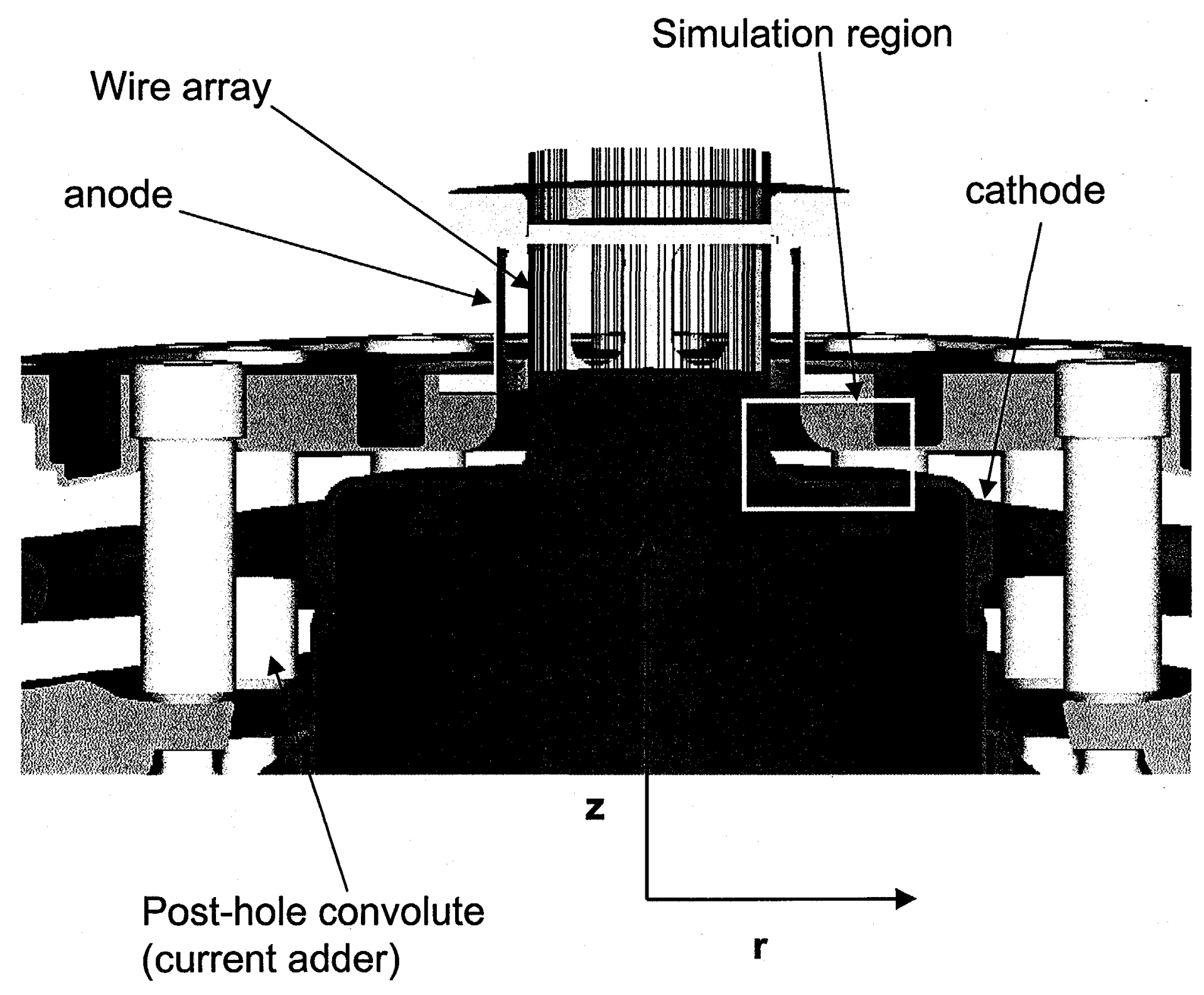




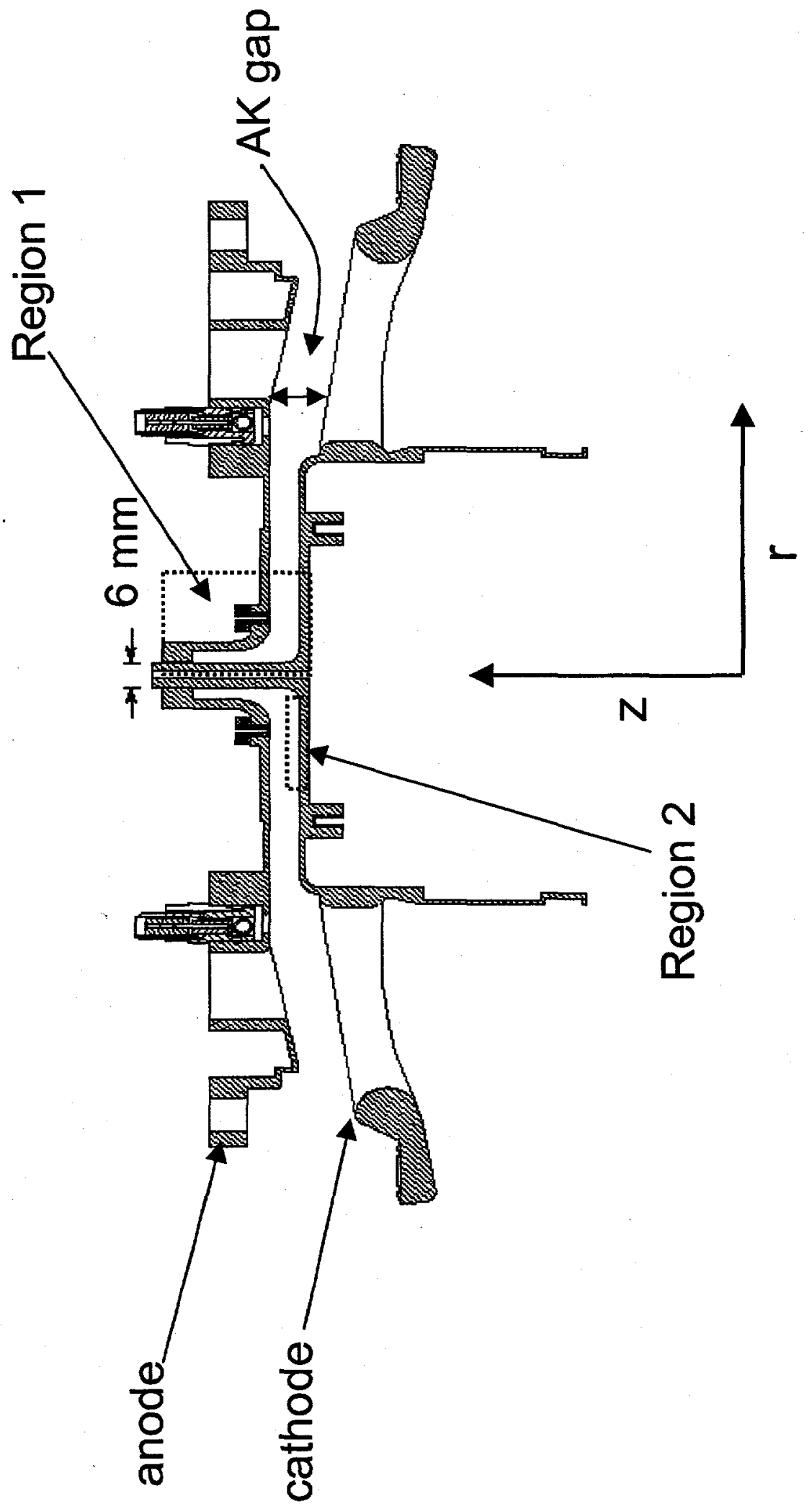




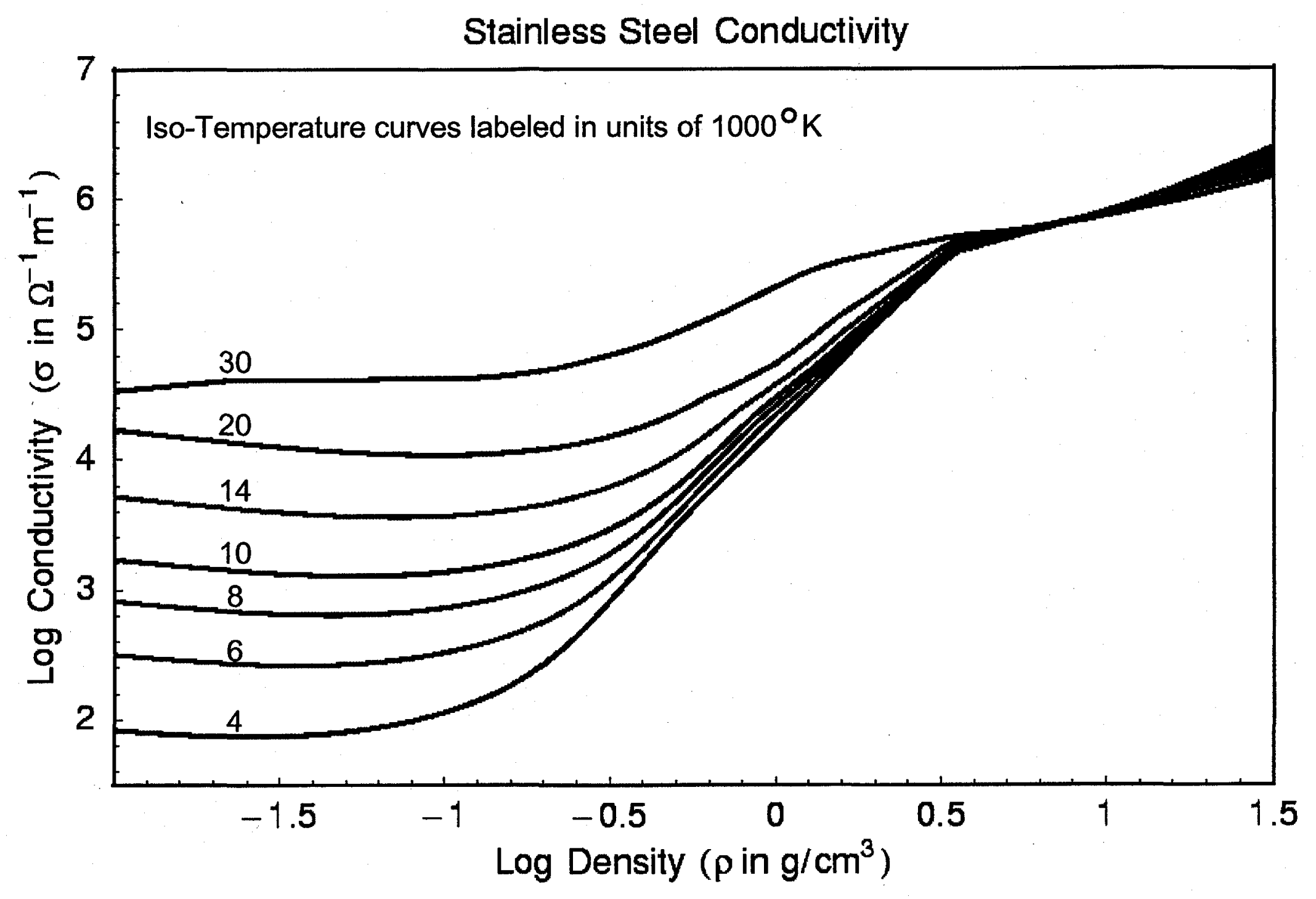




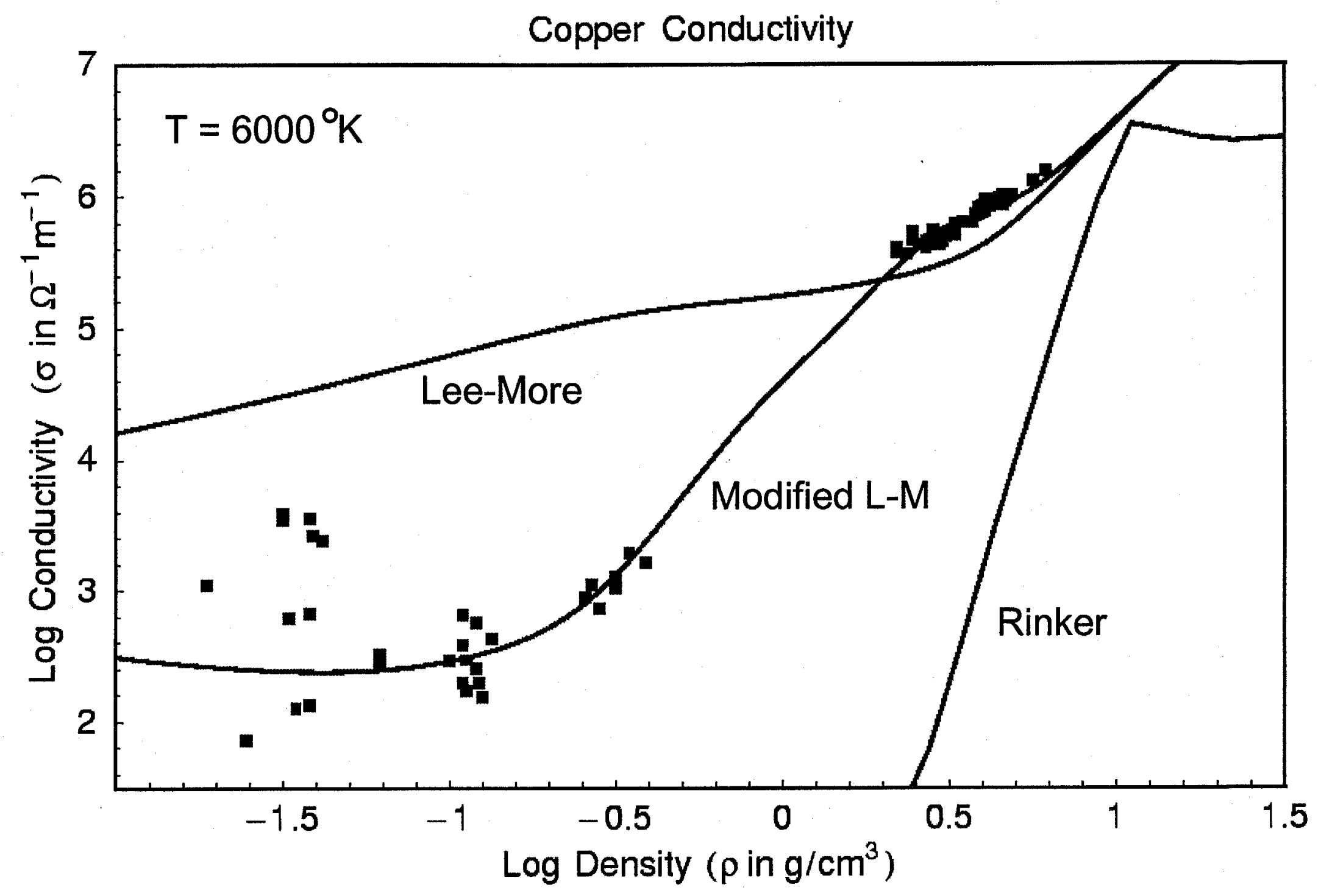


Cu SESAME 23334
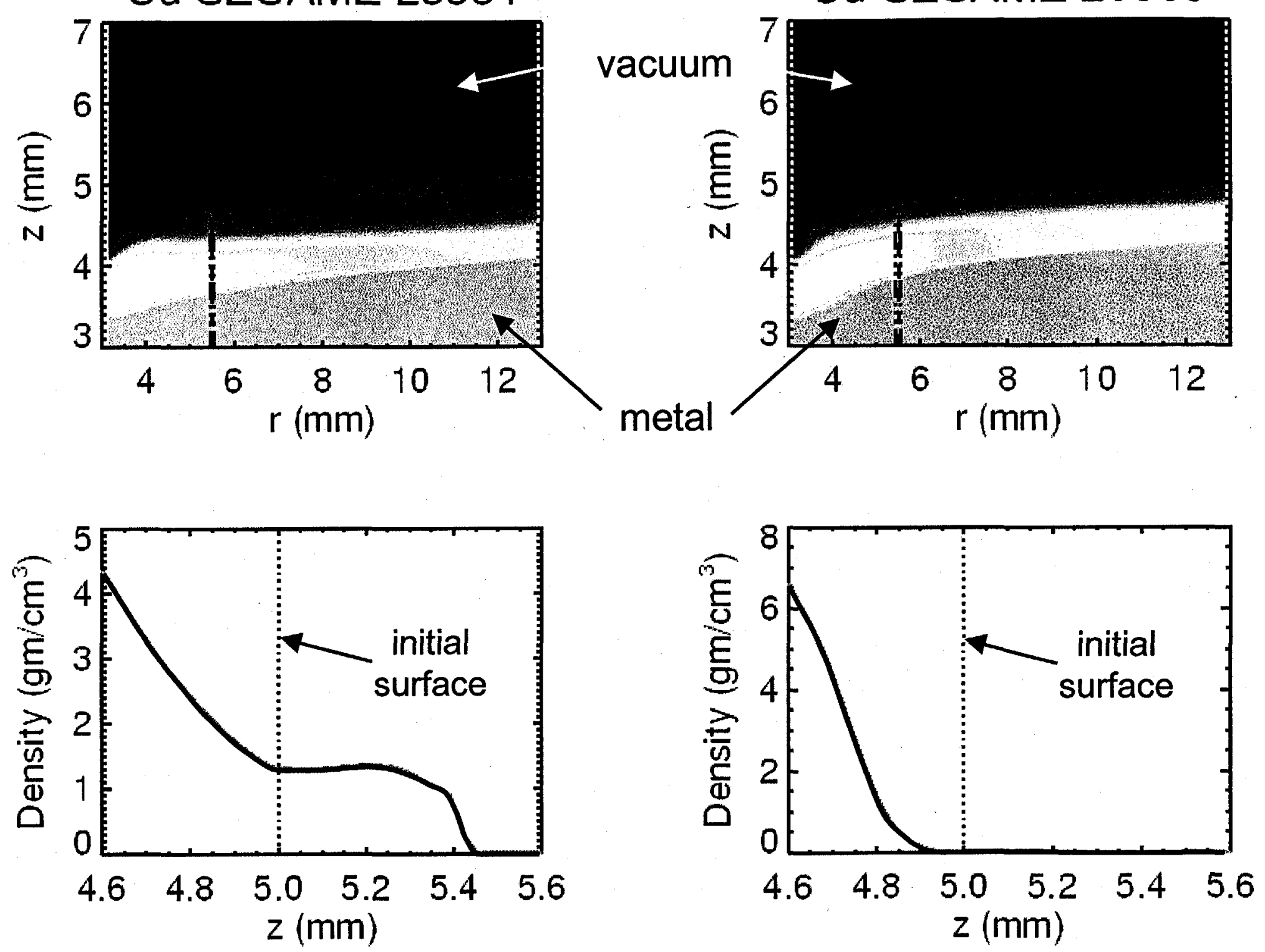

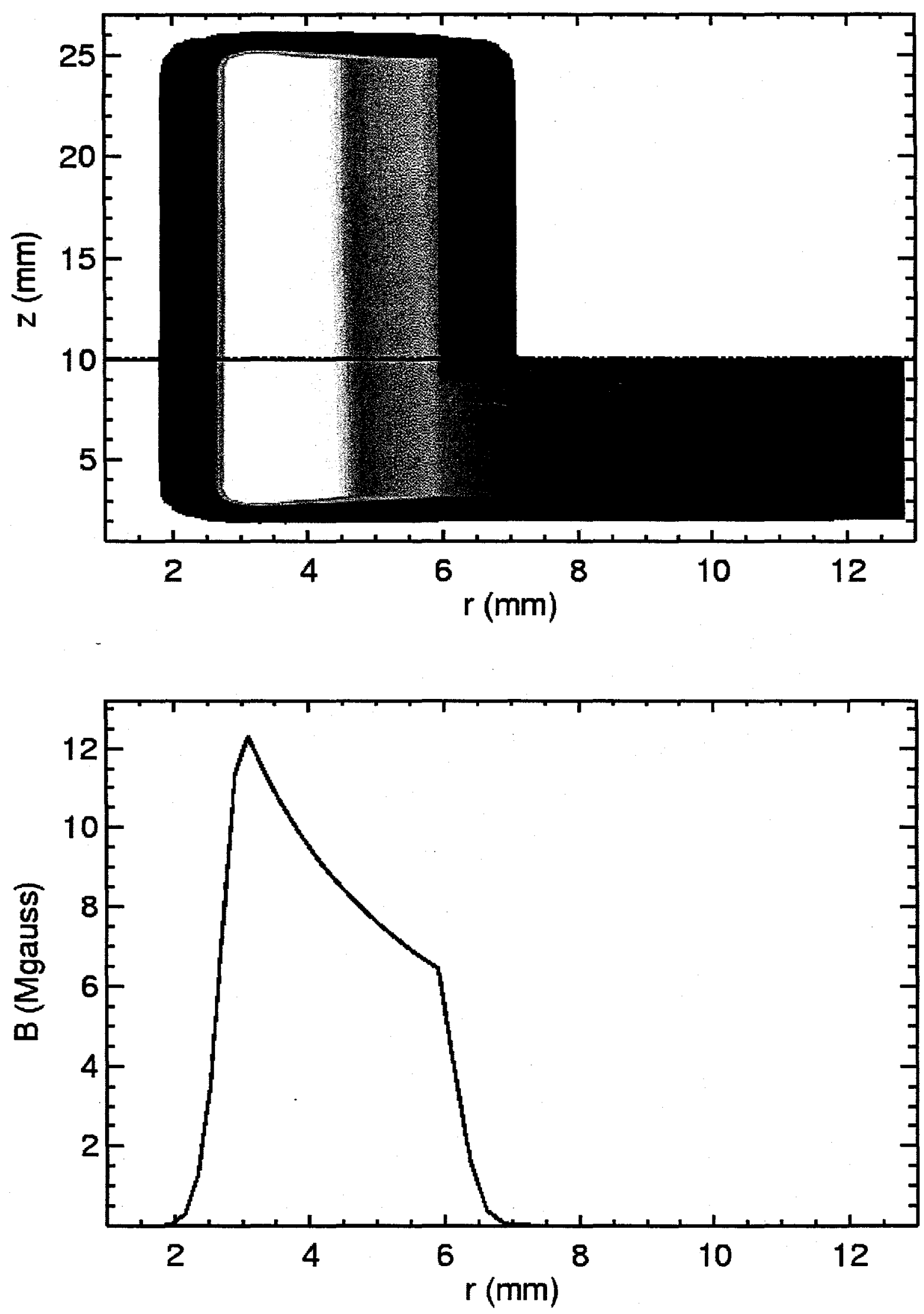


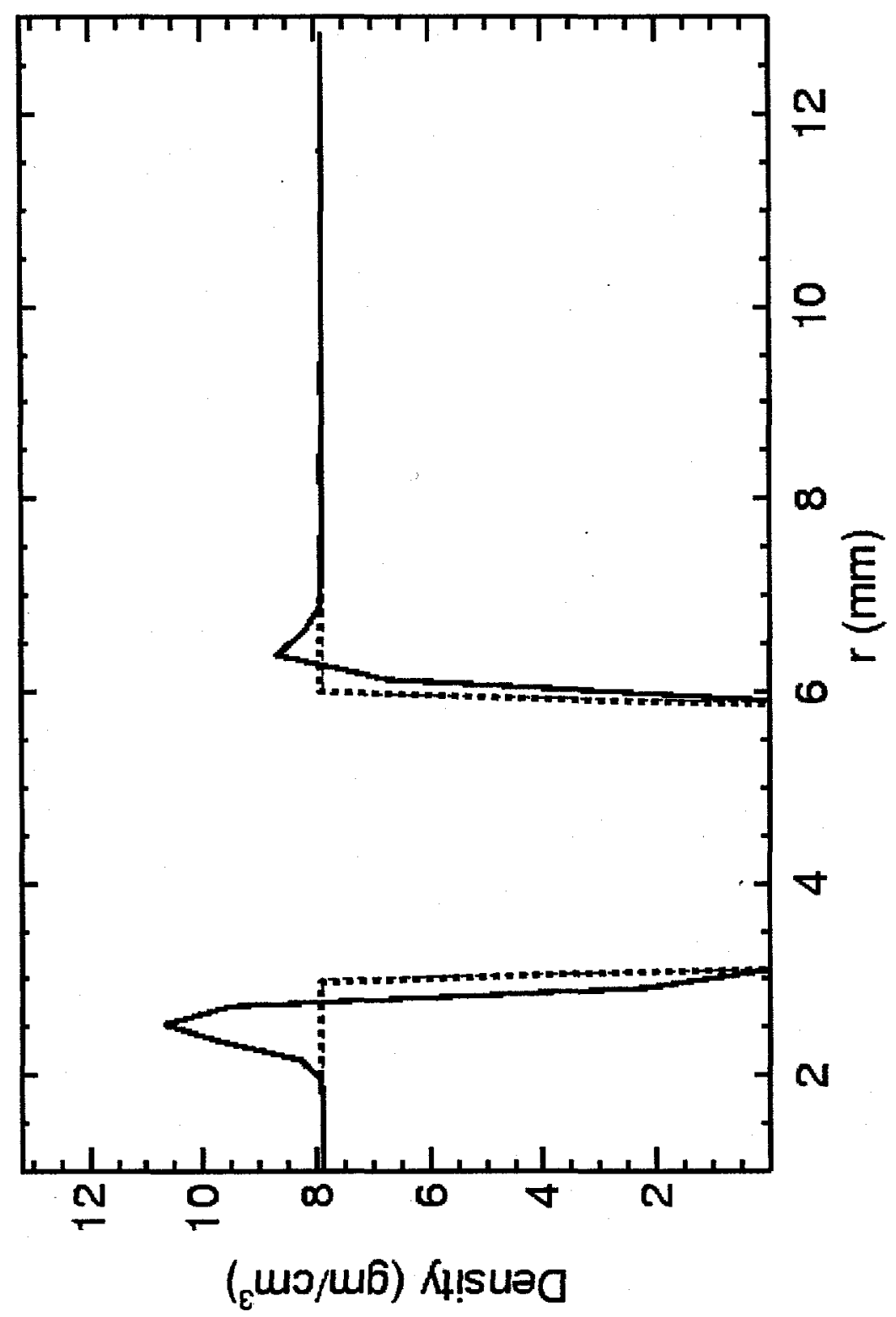




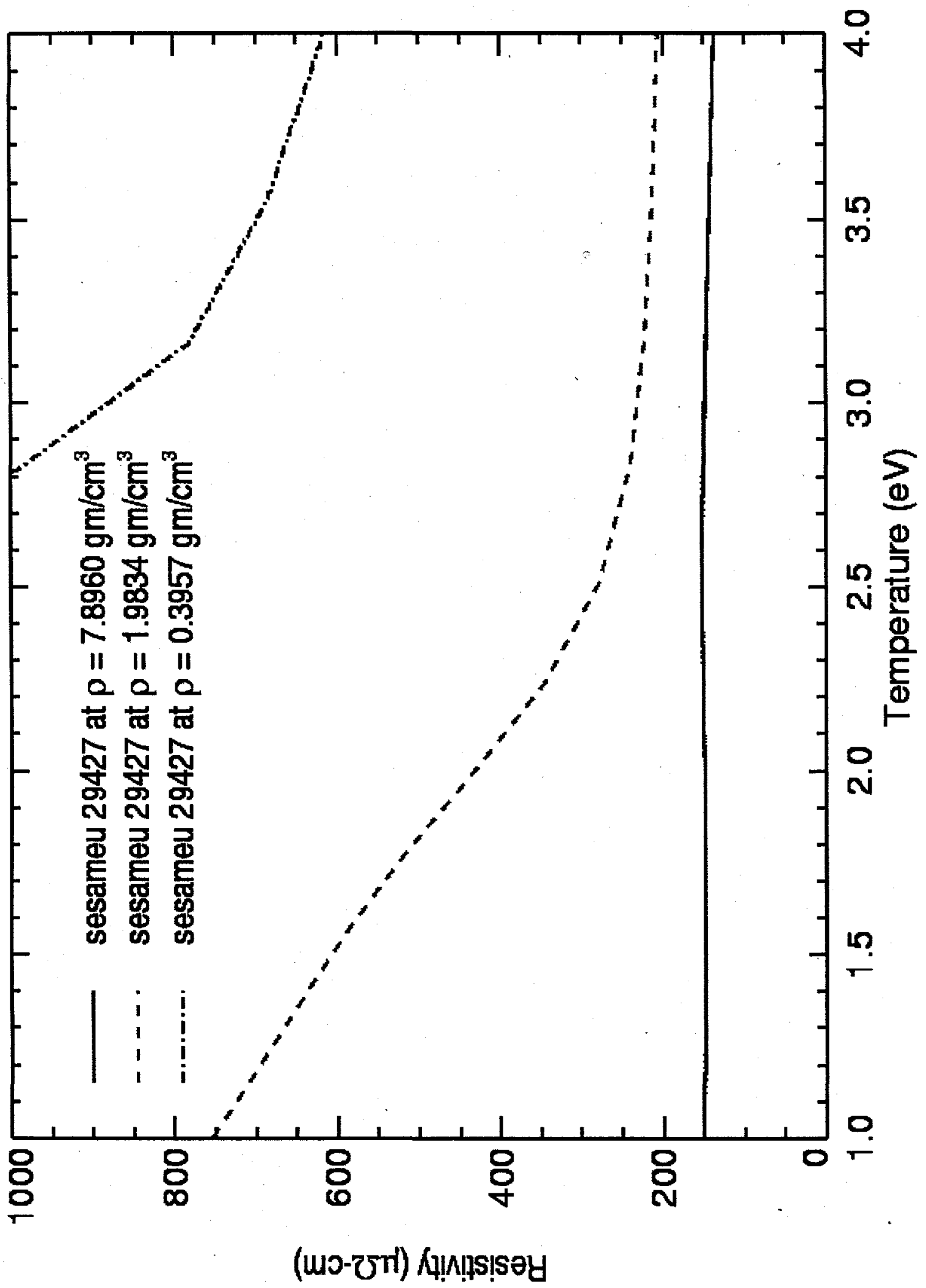




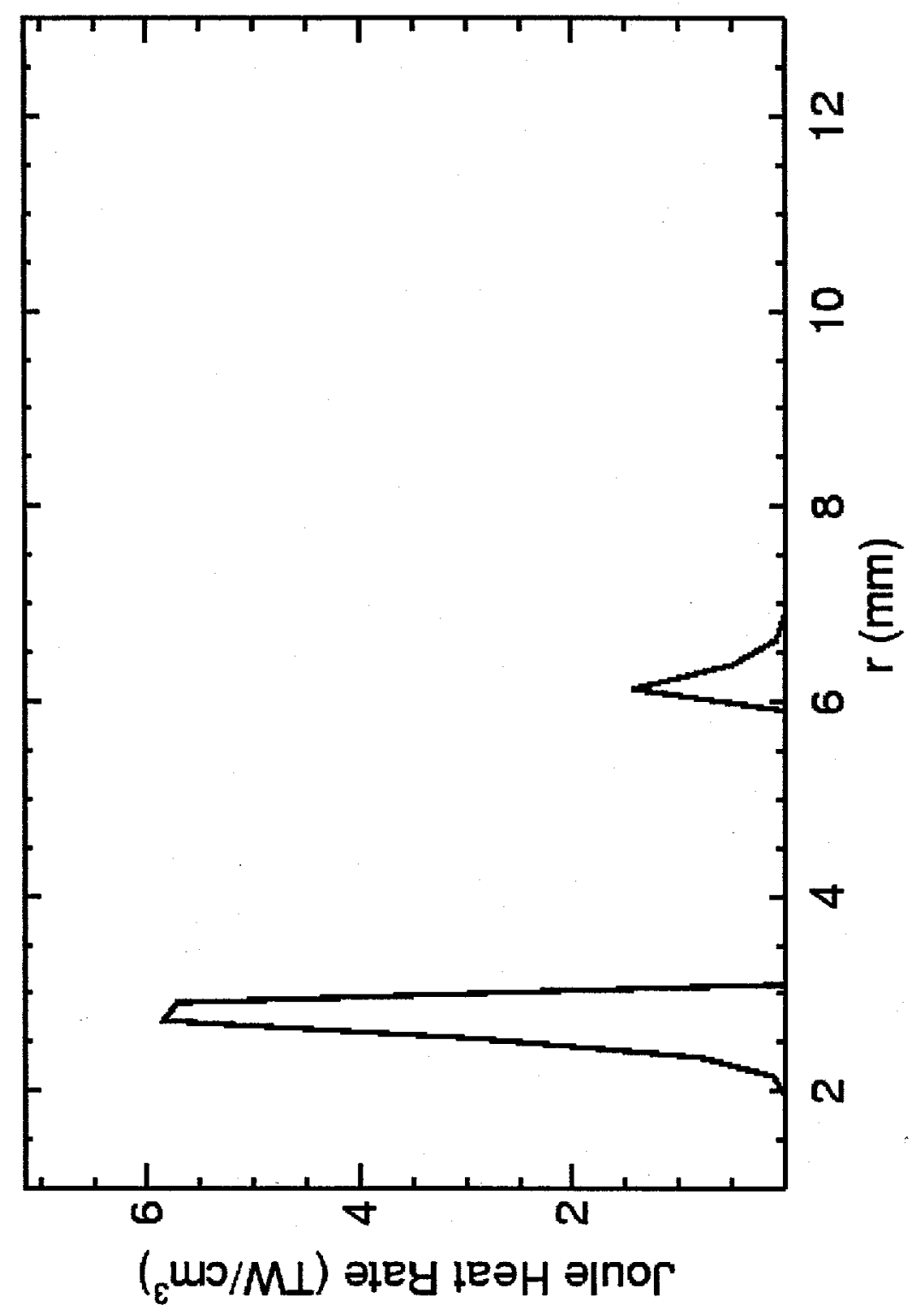




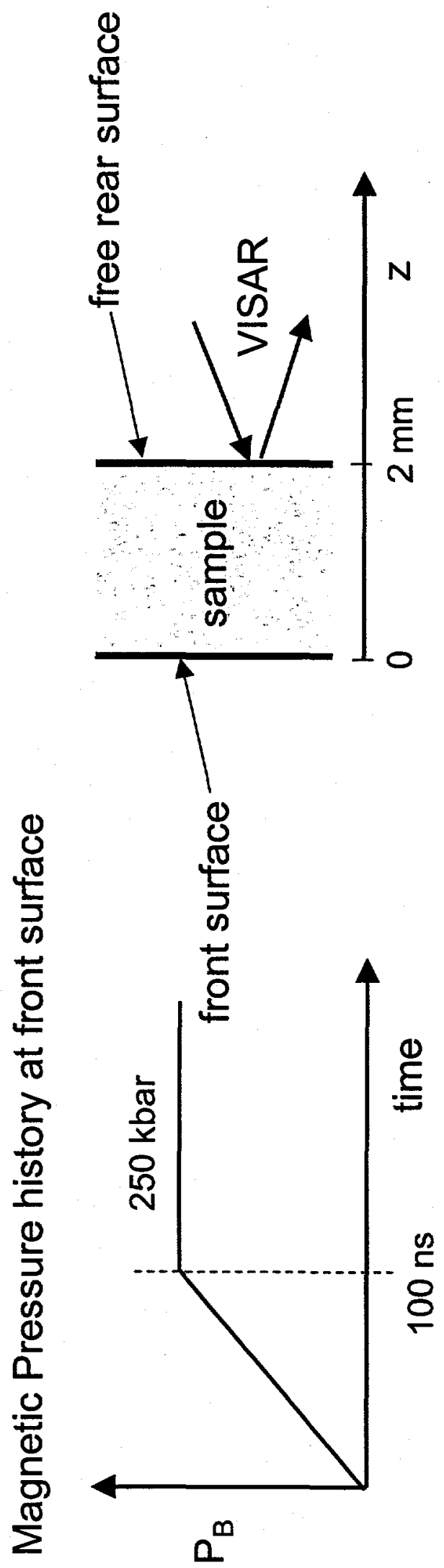




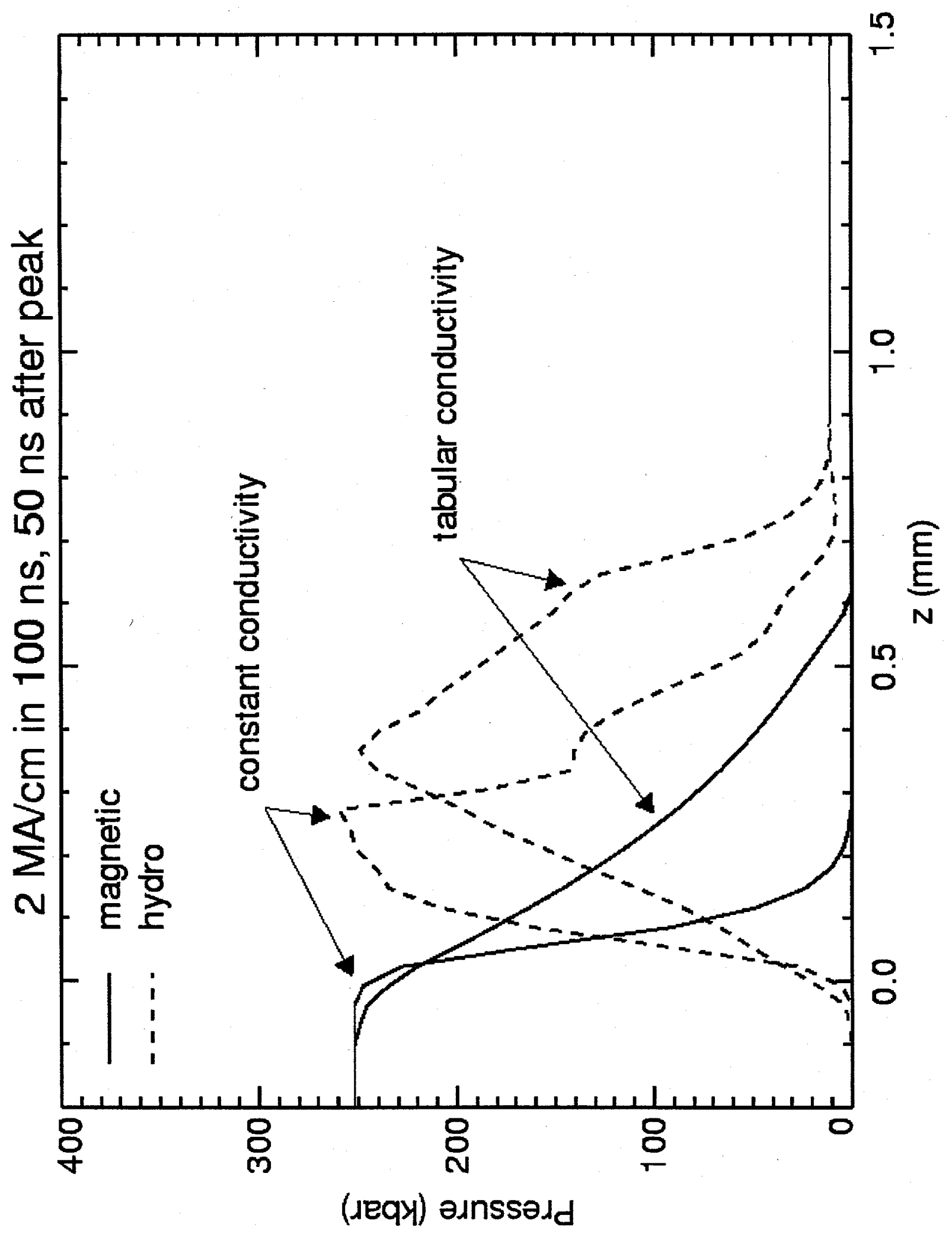




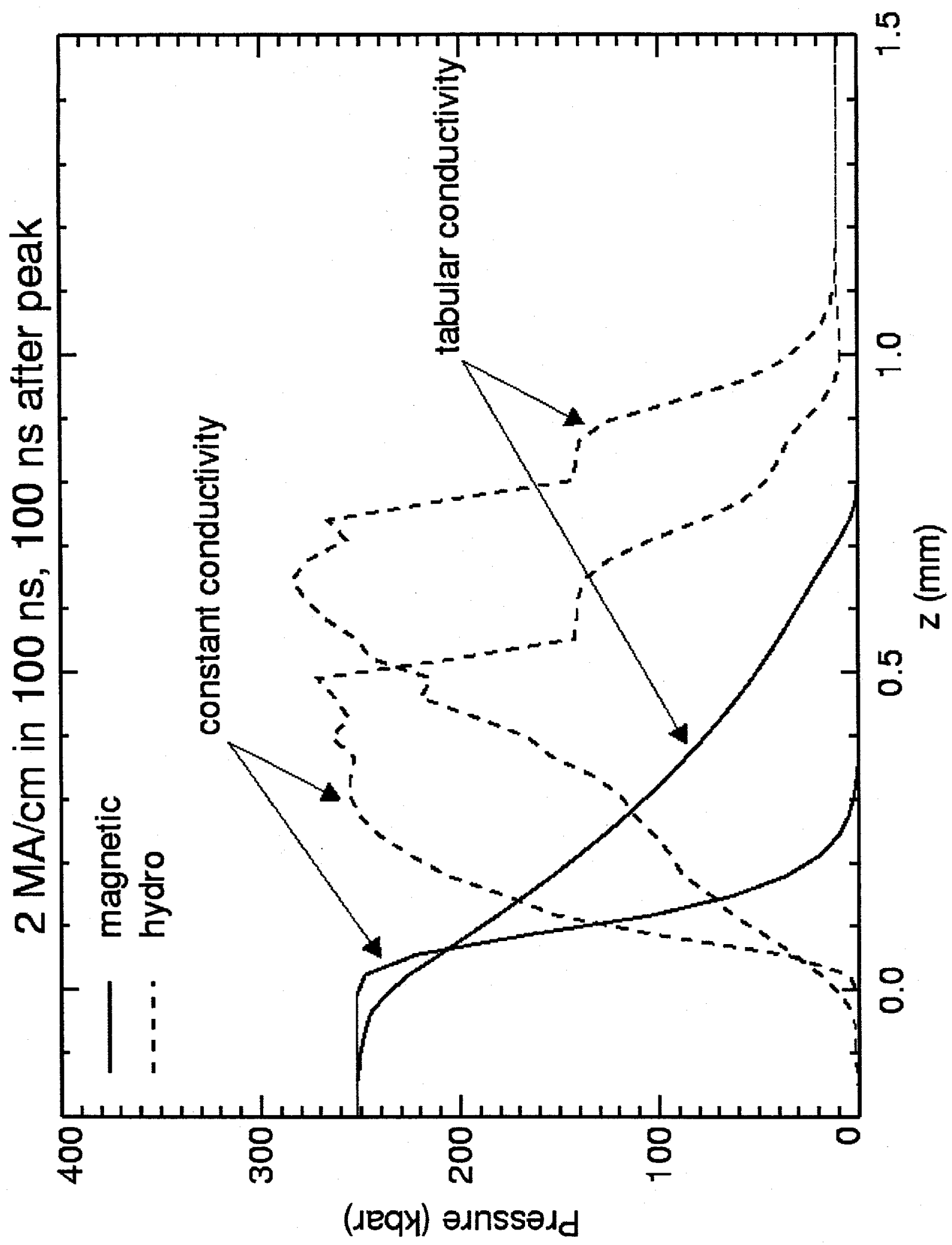




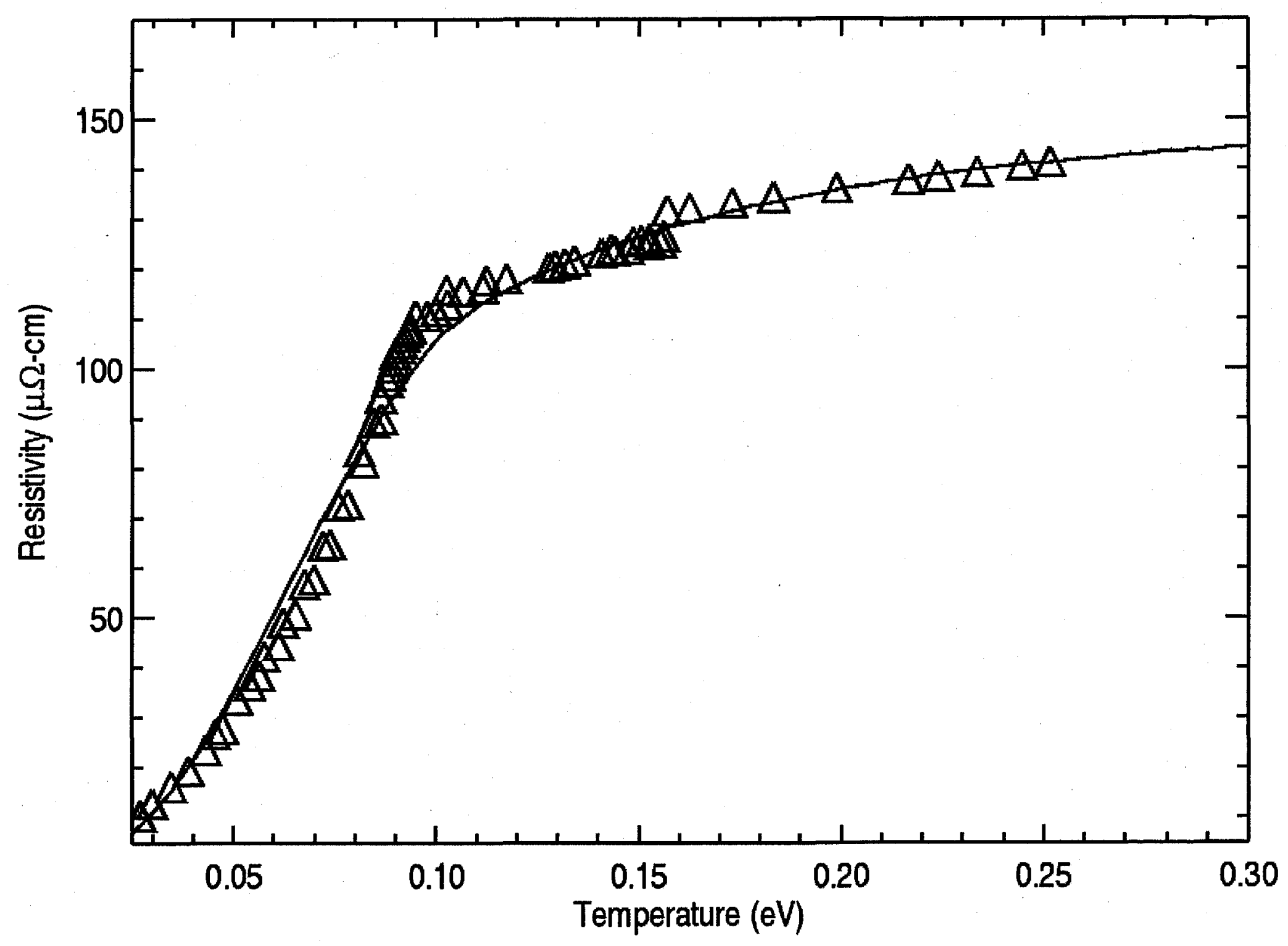




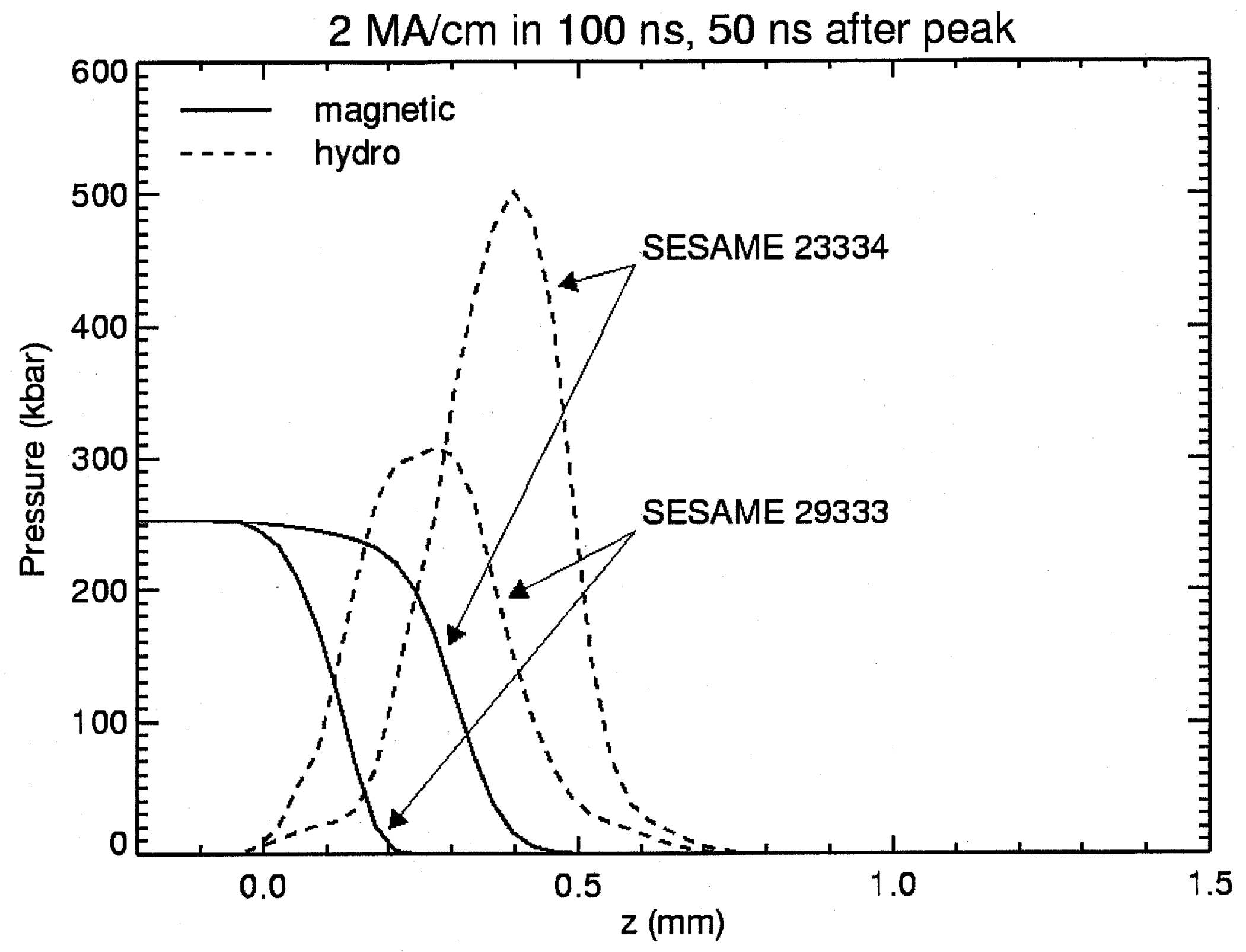




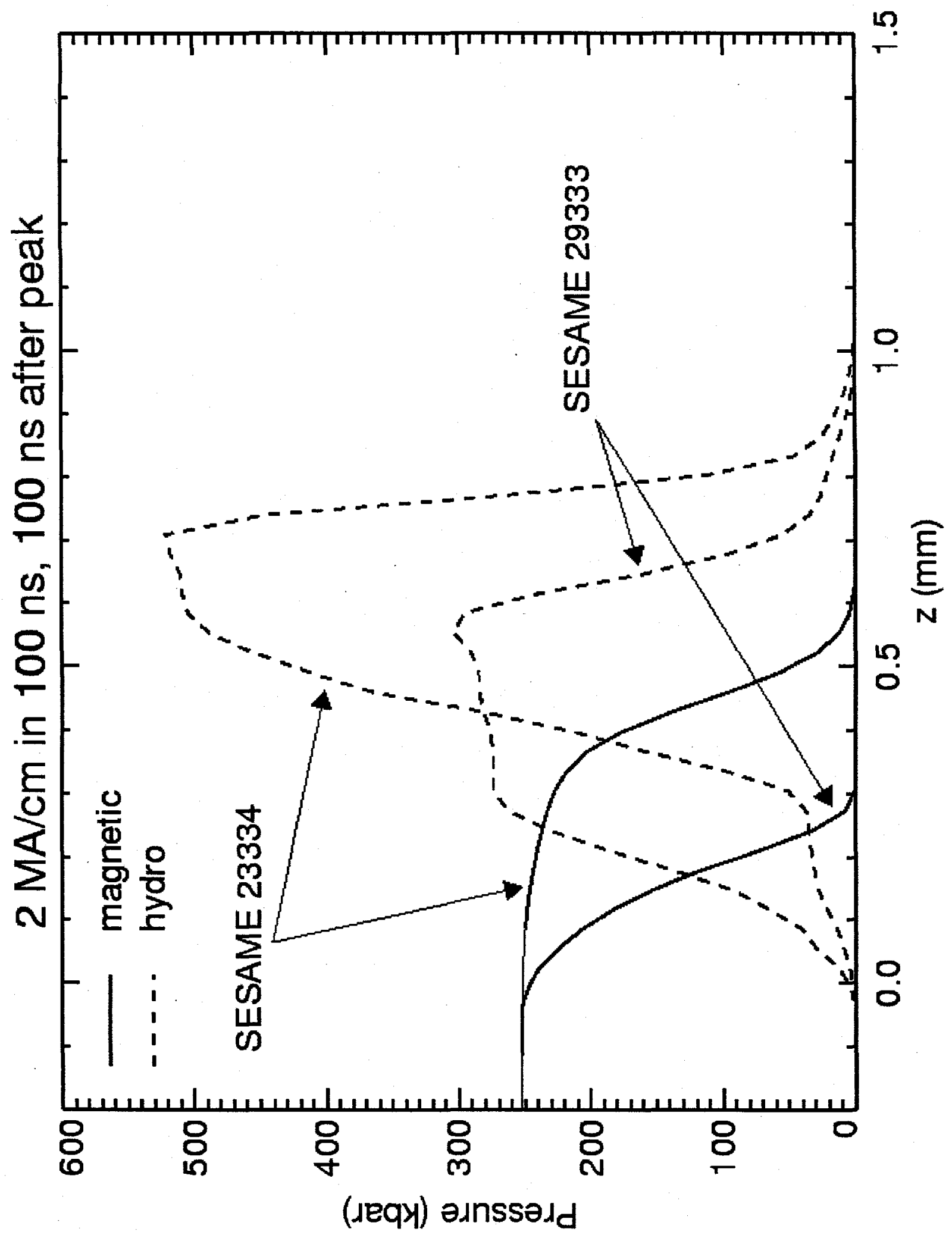

